REVIEW ARTICLE

\title{
Some Points to Ponder through Some New and Old Concepts in Sleep Medicine
}

\section{T. Mohan Kumar}

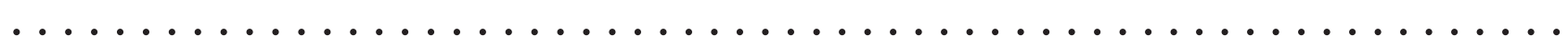

See end of article for

Indian J Sleep Med 2006; 1.2, 78-80

authors affiliations

Address for correspondence:

T. Mohan Kumar MD, ABIM, DPPR, FCCP, FNCCP

Senior Consultant Pulmonologist \& HOD,

Institute of Pulmonary Medicine \& Research,

Sri Ramakrishna Hospital,

Coimbatore 641044, Tamil Nadu

Email :drtmk@vsnl.net.in

\section{Introduction}

$\mathrm{S}$ leep medicine continues to evolve rapidly. Sleep is a resting state in which an individual becomes relatively quiescent and unaware of the environment. Theinterest in sleep medicinestarted taking momentum from seventies and we are now gaining more and more data on the same.

To quote $\mathrm{H}$ amlet, Act III, Scene 1: "to sleep; perchance to dream: ay, there is the rub; for in that sleep of death what dreams may come".

D uring sleep most physiological functions decrease, like breathing which becomes slower and deeper, may stop for short periods with significant dropsin respiration known as nocturnal desaturation. Sincethesleep disorders can occur in $2-4 \%$ of the adult population it assumes great significance.

So important that sleep disorders have become in clinical medicine, The Centers for Medicare and $M$ edicaid Services [CM C, USA] is considering the possibility of portable monitoring for determination of patients for CPAP. This seems logical as OSA is life threatening and CPAP at 9 to $10 \mathrm{~cm}$ of $\mathrm{H} 20$ is as good as lab titrated values. D espite this, the American A cademy of Sleep M edicine continues to oppose this portable monitoring and auto titration CPAP in the routine management of sleep apnea.

The epidemiology of sleep disordered breathing has changed over the years, and new effects are pouring in about changes in metabolic function and cardiovascular outcomes.

Prevalence of symptoms and risk of sleep apnea in primary care has been recently illustrated well in the article by N etzer NC (1).6223 patient forms were analyzed from USA, Spain and Germany from the patients who had come for hypertension, obesity, chronic snoring , sleepiness and a calculation of OSA was done. It was noted that the rates of frequent sleepiness and drowsy driving were very high. About a third warranted sleep apnea evaluation .Among snorers, 37\% of men and $27 \%$ of women were at high risk of OSA. The use of CPAP, in patients with heart failure, the improvement in blood pressure management and cardiac function is well documented $(2,3)$. In India, the prevalence in OSA in urban areas is equally disturbing (4). The prevalence rates for sleep disordered breathing in men aged 35 to 65 years is $19.5 \%$ and OSA $7.5 \%$. The data from other groups like Asians are also at increased risk for sleep apneas (5).T he exact figures from various centers with the same Berlin questionnaire has to be doneto get world wide data. 
What are the factors influencing breathing during sleep in adult healthy people? It has been proved beyond doubt that healthy males and females have no difference in oxygen desaturation during NREM or REM sleep( 6 , 7).There are definitely changes due to old age which have been demonstrated as changes in respiratory controller function occurring with age $(8,9)$. Alcohol reduces pharyngeal muscletone in healthy people, snoring appears where prolong apneas and poor sleep quality (10). Benzodiazepines have similar effects like alcohol (11).C affeine has a bad effect on sleep and has been extensively studied (12). M ore and more drug related studies in various patient groups are coming in to enhance our knowledge of sleep medicine.

Is there a genetic predilection for sleep apneas? Some authors think so, by demonstrating that many in the family are affected $(13,14)$.Both the symptoms (15) and sleep laboratory evidence (16) have been shown to present in families beyond doubt. Relatives of non obese obstructive sleep apnea patients have smaller upper airways and a different craniofacial morphological structure than matched controls.

Patients with COPD, with hypercapnia plus cor pulmonale [classical blue bloater if you see any] may have OSA $(17,18)$. Such patients have, what you call an 'overlap syndrome' [C O PD +O SA] .T his combination has important consequences in terms of morbidity and treatment. A saw tooth pattern in the $\mathrm{SaO} 2$ trace in a patient with COPD suggests that OSA is also present. If aCO PD patient with moderatesevereairflow obstruction has day sleepiness time suspect overlap syndrome and treat both simultaneously. Remember, also, that supplemental oxygen therapy alone is not the optimal treatment in these cases as nasal CPAP plus oxygen is the most efficient therapy (19). It is still debatable whether isolated nocturnal hypoxemia should be treated or not with nocturnal oxygen plus CPAP.

The controversy regarding whether fixed CPAP and auto CPAP has been raging for some time. In a classical study done in about 3 months time it was proved beyond doubt that both delivered equally efficacious treatment for the patients(20).But the point is that improved compliance is more in autoCPAP $(21,22)$. Still a lot of work is to be done especially in centers where they rely on CPAP in outpatient based approach.

In the era of travel to distant places and the ensuing jet lag there is a lot of interest in studying the effects especially in normal individuals. The jetlag syndrome occurs when the asynchrony occur in the person's internal circadian pacemaker and the external clock time secondary to rapid travel across several time zones. Symptoms include problems with sleep onset or maintenance, decreased alertness, decreased performance in the new time zone. Light is the most potent stimulus for shifting the circadian cycle .M elatonin appears to play an important role in synchronizing the suprachiasmic nucleus of the hypothalamus [internal pacemaker] to the environment. M ore studies are needed to answer some of the regulatory mechanisms in this connection (23). Interestingly the jetlag worsens with age.

Sleepwalking in adults is interesting, as not all adults had the same problem when they were children. Sleep walking occurs during slow wave sleep and can occur in stage2 and second half of the night (24).It is interesting to note that CPAP can aggravate sleep walking in people with prior sleep deprivation with resulting slow wave sleep rebound.

The metabolic changes in sleep apnea is being studied extensively and leptin seems to have more role in this , especially with a dip in level in the morning in obese OSA patients (25). The effect of treatment for sleep disorders on leptin levels is just coming in (26)

In this short essay, I have put in some of the observations in sleep, or the lack of it which has surfaced as a major health problem. Considering the importance of sleep in the well being of any man or woman, all physicians require a practical working knowledge of sleep disorders. This article is only the tip of the iceberg detailing the points in vast sea of sleep medicine, but $I$ hope this will raise a spark of interest going through old as well as new references. I gave the old references to appreciate what we have gone through the years in the study and understanding of sleep medicine.

\section{Authors Affiliations}

Dr. T. Mohan Kumar MD, ABIM, DPPR, FCCP, FNCCP

Senior Consultant Pulmonologist \& HOD, Institute of Pulmonary Medicine \& Research, Sri Ramakrishna Hospital, Coimbatore 641044, Tamil Nadu Email: drtmk@vsnl.net.in

\section{References}

1. Prevalence of symptoms and risk of sleep apnea in primary care, Netzer NC, Chest 2003 124:1406-1414,

2. Kaneko Y, Floras JS, Usui K et al, Cardiovascular effects of 
continuous positive airway pressure in patients in patients with heart failure and obstructive sleep apnea, $N$ Engl J Med 2003; 348:1233-1241,

3. Becker HF, Jerrentrup A, Ploch $T$ et al, Effect of nasal continuous positive airway pressure treatment on blood pressure in patients with obstructive sleep apnea. Circulation 2003; 107:68-78,

4. Udwadia ZF, Doshi AV, Lonkar SG et al, Prevalance of sleep disordered breathing and sleep apnea in middle aged urban Indian men, Am J Respir Crit Care Med 2004 169:168-173

5. Ong KC, Clerk AA :Comparison of the severity of sleep disordered breathing in asian and Caucasian patients seen at sleep disorders center: Respir Med 1998; 92:843-848.

6. Block AJ, Boysen PC, Wynne JW, Hunt LA, Sleep apnoea, hypopnoea and oxygen desaturation in normal subjects - a strong male predominance, N Engl J Med 1979; 300:513517.

7. Catterall JR, Calverely PMA, Shapiro CM, Breathing and oxygenation during sleep are similar in normal men and women, Am Rev Respir Dis 1985; 132:86-92

8. Shore ET, Milman RP, Silage DA, Chung DC, Pack AL, Ventilatory and arousal patterns during sleep in normal young and elderly subjects. J Appl Physiol 59:1985; 16071615.

9. Kreiger J, Maughin P, Kuntz D. Les modifictios respiratoires au cour du sommeil du sujet age normah, Rev Electroencephalogr N europhysiol Clin 10: 1980; 175-185.

10. Taasan V, Block AJ, Boysen PG, Wynne JW, Alcohol increases sleep apnoea and oxygen desaturation in asymptomatic men, Am J Med :1981; 71:240-245.

11. Cirignotta F, Mondoni S, Zucconi et al, snoring and sleep apnea: effects of lorazapam and mazindol evaluated by means of snoring and sleep apnea monitoring. Bull Eur Physiopathol Respir 1982; 18:113-134.

12. Curatolo PW, Robertson $D$, The health consequences of caffeine. Ann Intern Med 1983; 98:641-653.

13. Manon Espiillat R, Gothe B, Adams N, Newman C, Ruff R, familial aggraggates in obstructive sleep apnea syndrome. Chest 1995; 107:1545-1551.

14. El Bayadi S, Millman RP, Tishler PV et al, A family study of sleep apnea, anatomic and physiologic interactions, Chest 1990; 98:554-559.

15. Mathur R, Dougles NJ, Family studies in patients with sleep apnea-hypopnea syndrome, Ann Intern Med 1995; 122:174-178.

16. Douglas NJ , Luke $M$, Mathur R, Is sleep apnoea hypopnea syndrome inherited, Thorax :1993; 48:719-721.

17. Douglas NJ, Sleep in patients with chronic pulmonary disease, Clin Chest Med 1998; 19:115-125.

18. Cooper CB, Howard $P, A n$ analysis of sequential physiologic changes in hypoxic cor pulmonale during long term oxygen therapy, Chest 1991; 100:76-80.

19. Sampol G, Seagles MT, Roca A et al, Nasal continuous positive airway pressure with supplemental oxygen in coexistant sleep apnea-hypopnea syndrome and svere chronic obstructive pulmonary disease, Eur Respir 1996; 9:111-116.

20. Senn O, Brack T, Mathew F et al, Randomized short term trial of two auto CPAP devices versus fixed continuous positive airway pressure for the treatment of sleep apnea, Am J Respir Crit Care Med 2003; 168:1506-1511.

21. Randerath W, Schaerder O, Galetke WW ET AL, Autoadjusting CPAP therapy based on impedence efficacy, compliance and acceptance, Am J Crit Care Med 2001; 163:652-657.

22. Massie CA, Mc Ardle N, Hart RW et al, Comparison between automatic and fixed positive airway pressure in the home, Am J Respir Crit Care Med 2003; 167:20-23.

23. Moline ML, Pollack $C P$, Monk TH et al, Age related differences In recovery from simulated jet lag, Sleep 1991; 14:42-48

24. Schenck $\mathbf{C H}$, Milner DM, Hurwitz TD et al, A polysomnographic and clinical report of sleep related injury in 100 adult patients, Am J Psych 1989; 146: 146:11661172.

25. Patel SR, Palmer LJ, Larkin EK et al, Relationship between OSA and diurnal leptin rhythms, Sleep 2004; 27:235239.

26. Sanner BM, Kolhosser P, Buechner N et al, Influence of treatment in leptin levels in patients with obstructive sleep apnea, Eur Respir 2004; 23:601-604. 